\title{
LOW TEMPERATURE THERMAL EXPANSION OF G-10 PLASTIC AND MYLAR
}

\author{
David Bell \\ May 24, 1993
}

D-Zero Engineering Note 3740.000-EN-340

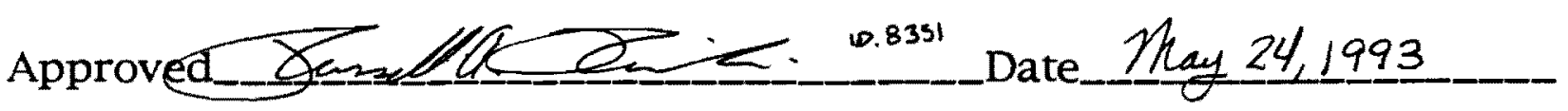




\section{Introduction}

This engineering note is a summary of test information and conclusions from the thermal expansion tests conducted at D-0 during the fall of 1992. Each test was conducted separately but using the same basic procedure and equipment. While information on material properties at room temperature and above for these products is quite well doccumented, the companies producing these products had no available data about the thermal properties of these materials at cryogenic temperatures. This lack of readily available information prompted these tests to determine the accuracy of using the elevated temperature data for lower temperatures also. The results of each test were written up separately as stand alone short reports for immediate use in the design stages of the V.L.P.C. cryostat cassette. Both short reports are gathered here for convenient reference. 


\section{THERMAL EXPANSION TEST OF G-10 PLASTIC FOR V.L.P.C. TEST PROCEDURE}

A test to determine thermal expansion of a sample tube of G-10 plastic was conducted in the DO tech lab (8/21/92). The experimental data was obtained by measuring the initial length and temperature of the tube at several points, filling the tube with liquid nitrogen. allowing the tube to cool and then measuring again. A sketch of the sample is shown in figure 1. The tube was approximately 1.5 inches in diameter with a 0.015 inch wall thickness and a length of 18 inches. A 0.25 inch solid G-10 disk was bonded to the bottom. Three reference temperatures were taken with thermocouples taped to the outside of the tube before it was wrapped in insulation. These thermocouples are referred to as $T_{1}, T_{2}$, and $T_{3}$. $T_{1}$ was obtained 2 " from the top, $T_{2} 9^{\prime \prime}$ from the top and $T_{4}$ was taken 16" from the top. A fourth temperature, $T_{4}$, was taken on the inside of the tube about 4 inches down, in $\mathrm{LN}_{2}$.

\section{EXPECTED RESULTS}

The expected thermal contraction for a tube made of G-10 is $\Delta L / L=0.0026 \mathrm{in} . / \mathrm{in}$. This value was obtained from the graph of a glass fiber reinforced polyester rod in the chart of "thermal contraction of various materials from room temperature to cryogenic temperatures." From this data, a contraction of 0.0475 inches was expected. The thermal expansion coefficient, $\alpha$, is between $1 \times 10^{-5}$ in./in. ${ }^{\circ} \mathrm{C}$ and $1.5 \times 10^{-5} \mathrm{in} . / \mathrm{in} .{ }^{\circ} \mathrm{C}$. as seen in a plastics data book reference. A change in temperature of $\Delta \mathrm{T}=216^{\circ} \mathrm{C}$ from a room temperature of $20^{\circ} \mathrm{C}$ to $-196^{\circ} \mathrm{C}$ at $\mathrm{LN}_{2}$ temperature results in values for $\Delta \mathrm{L} / \mathrm{L}=\alpha \Delta \mathrm{T}$ ranging from approximately $0.0022 \mathrm{in.} / \mathrm{in}$. to 0.0032 $\mathrm{in} . / \mathrm{in}$. The initially calculated value of 0.0026 is within this range and can be taken to be reasonable.

\section{ACTUAL RESULTS}

The change in length for the G-10 sample was measured to be $0.050 \mathrm{in}$. This corresponds to a $\Delta \mathrm{L} / \mathrm{L}$ of $0.050 \mathrm{in} . / 18.250 \mathrm{in} .=$ $0.00274 \mathrm{in.} / \mathrm{in}$. The final temperatures are listed in table 1. Assuming an internal tube temperature of $-320^{\circ} \mathrm{F}$ at each thermocouple location an average temperature of $-308.7^{\circ} \mathrm{F}$ was 
calculated. With this, a $\Delta T$ of $385.7^{\circ} \mathrm{F}=214.3^{\circ} \mathrm{C}$. For these values, $\alpha=(\Delta L / L) / \Delta T=1.28 \times 10^{-5} \mathrm{in} . / \mathrm{in}{ }^{\circ} \mathrm{C}$.

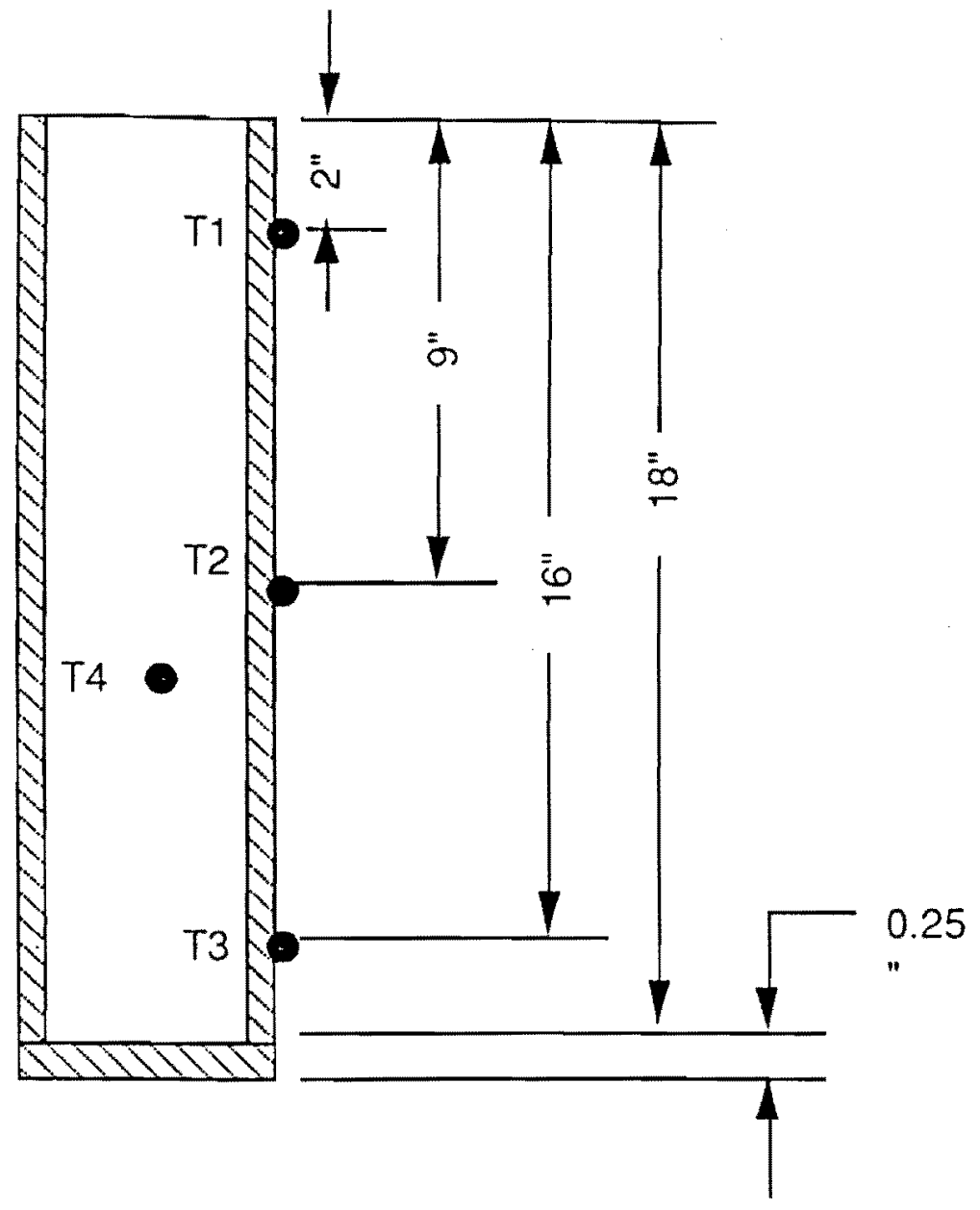

FIGURE 1 - TUBE SKETCH

TABLE 1 - LENGTH AND TEMPERATURE DATA (all temperatures in table are in ${ }^{\circ} \mathrm{F}$ ) $\begin{array}{llllll}\text { Length } & \mathrm{T} 1 & \mathrm{~T} 2 & \mathrm{~T} 3 & \mathrm{~T} 4 & \mathrm{~T} \text { Avg. }\end{array}$ (in.)

Warm

$18.715 \quad 75.5$

75.2

74.8

78.5

Warm

$18.715 \quad 78$

77

75

77

Cold

$18.665-282$

.290

$-320$

$-319$

$-308.7$

Warm

$18.717 \quad 75$

7.5

75

75 


\section{THERMAL EXPANSION TEST OF MYLAR TUBING FOR V.L.P.C.}

\section{TEST PROCEDURE}

A test to determine the thermal expansion of a sample of mylar was conducted by Delmar Miller in the D-Zero tech lab (9/21/92 \& $9 / 22 / 92)$. The experimental data was obtained by measuring the initial length of the tube and its temperature at several points, filling the tube with liquid nitrogen, allowing the tube to cool and then measuring again. Figure 1 shows a sketch of the sample. The tube was approximately 1.6 inches in diameter with a 0.010 inch wall thickness. Due to the thin material, a G-10 disk was used as a collar cap for the purpose of measuring the height. The reference height of the table was 0.4 in., and since the nominal measured height of the tube was 17.9 in., a live length of about 17.5 inches was the actual length of the tube.

Testing equipment for this procedure included four thermocouples and a distance measuring probe. Three reference temperatures were taken with thermocouples taped to the outside of the tube, and a fourth inside the tube. The outer thermocouples are referred to as $\mathrm{T} 1$, T2, and T3. T1 was obtained 2" from the top, T2 was located 8" from the top, and T3 was taken 14" from the top. A fourth temperature, $\mathrm{T} 4$, was taken on the inside of the tube about 8 inches down, in $\mathrm{LN}_{2}$ when cooled down. The tube was wrapped in insulation after the thermocouples were placed. Temperatures were recorded at room temperature before cooling the tube and after cooling with $\mathrm{LN}_{2}$. The liquid on the inside should all be the same temperature at every point, and it is assumed that the wall internal surface is at the liquid temperature. The final temperature for the tube wall was then assumed to be the "grand" average of the mean wall temperatures at each of the thermocouples. This value was determined by averaging the temperature at each thermocouple on the wall surface with the internal temperature and then taking the average of these three values.

\section{EXPECTED RESULTS}

The expected thermal contraction for a mylar tube is $\alpha=(\Delta \mathrm{L} / \mathrm{L}) / \Delta \mathrm{T}=1.7 \times 10-5 \mathrm{in} . /$ in. $\mathrm{K}$. This value was obtained from design charts for $30^{\circ} \mathrm{C}$ to $50^{\circ} \mathrm{C}$ provided by Del Allspach, however the data did not extend to lower temperatures. This is the only value for which the manufacturer has published any data for thermal coefficients of expansion. The manufacturer says that mylar does 
undergo some residual shrinkage at high temperatures (above $150^{\circ} \mathrm{C}$ for this material), but that clearly is not a concern for the VLPC. DuPont has no other available data about thermal expansion for mylar. A change in temperature of $\Delta \mathrm{T}=220^{\circ} \mathrm{C}$ from an average room temperature of about $24^{\circ} \mathrm{C}$ to $-196^{\circ} \mathrm{C}$ at $\mathrm{LN}_{2}$ temperature results in the calculated value of $\Delta \mathrm{L} / \mathrm{L}=\alpha \Delta t$ being approximately 0.00375 in./in. for a total expansion of 0.065 inches.

\section{ACTUAL RESULTS}

Data was collected in tests run on two consecutive days as mentioned above. For the data taken on $9 / 21$, there were two different readings taken. The first reading was during the cool down. Delmar noticed the quick drop in temperatures while filling the tube and took a reading when there was about two inches of $\mathrm{LN}_{2}$ in the bottom of the tube. The readings at this point resulted in a contracton of $0.053 \mathrm{in}$. and an average temperature of $-185^{\circ} \mathrm{F}$ leading to an $\alpha=(\Delta \mathrm{L} / \mathrm{L}) / \Delta \mathrm{T}$ of approximately $2.095 \times 10-5 \mathrm{in} /$ in $\mathrm{K}$. The second reading was taken after the tube had been filled and showed a contraction of $0.076 \mathrm{in}$. at an average temperature of $-288^{\circ} \mathrm{F}$. From this data, an $\alpha$ value of $2.15 \times 10-5$ in/in $\mathrm{K}$ was calculated. The results for the test on $9 / 22$ showed an average temperature of about $-297^{\circ} \mathrm{F}$ and the calculated value of $\alpha$ was $1.94 \times 10-5$ in $/ \mathrm{K}$.

Several interesting and surprising patterns were brought to light in these results. First, the values for the thermal expansion coefficient calculated here were larger than the higher temperature published information, and this is surprising as most materials are generally expected to expand more at higher temperatures. This could possibly be a result of averaging the temperatures, as this average may not necessarily give an accurate distribution of the actual temperatures. The test results had a somewhat surprising pattern for temperature readings from the thermocouples. For the first reading (during the filling of the tube) on $9 / 21$, the temperatures of the thermocouples on the outside increased toward the top of the tube. This can be explained by air currents moving down the insulation warming the tube and heat conduction down the tube. For both tests taken after the tube was full of LN2 and readings stabilized, the middle temperature was the lowest, and the bottom temperature was the warmest. Perhaps this can be explained by heat transfer from both the top of the tube into the air and from the bottom of the tube to the table. 

D. Miller/
D. Bell
$9 / 30 / 92$

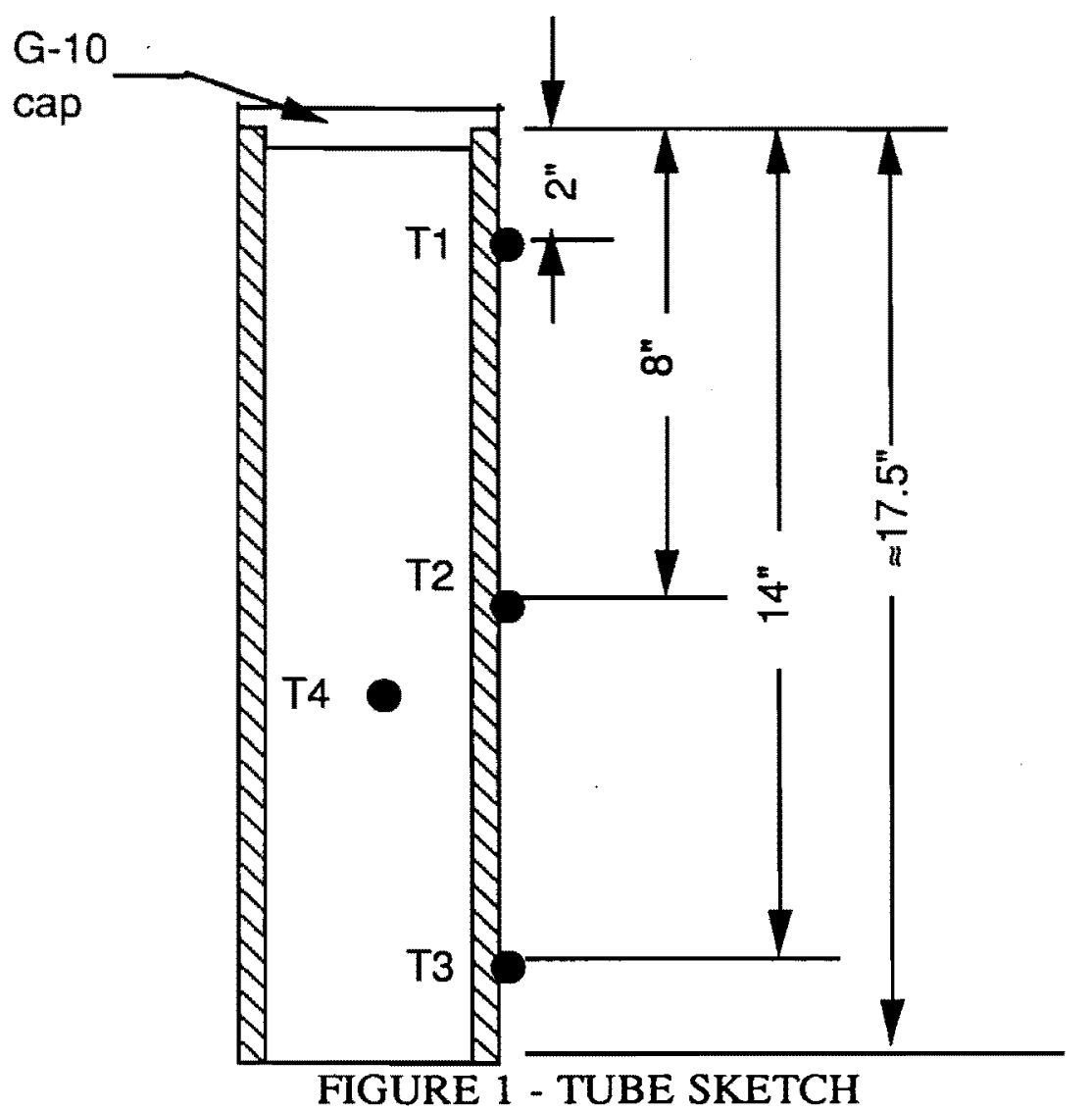

\section{TABLE 1 - LENGTH AND TEMPERATURE DATA}

\section{(all temperatures in table are in ${ }^{\circ} \mathrm{F}$ )}

$\begin{array}{lllll}\text { Collar } & \text { T1 } & \text { T2 } & \text { T3 } & \text { T4 }\end{array}$ Height (in.)

Warm

$9 / 21$

Cold

$9 / 21$

Cold

$9 / 21$

Warm

$9 / 22$

Cold

9/22

$17.913 \quad 75$

74

75

$-133$

$-212$

$17.837-256$

$-279$

$-240$

$17.908 \quad 77$

76

75

$\begin{array}{ll}17.839 & -270\end{array}$

$-302$

$-249$

$-239$

$-185.17$

$-318$

$-304.83$

76

76

$-320$

$-296.83$ 